\title{
Go-green manufacturing holons: a step towards sustainable manufacturing operations control
}

Damien Trentesaux ${ }^{1 *}$, Adriana Giret ${ }^{2}$

LAMIH, UMR CNRS 8201, University of Valenciennes and Hainaut-Cambrésis, UVHC, Le Mont Houy, 59313

Valenciennes Cedex, France

Damien.Trentesaux@univ-valenciennes.fr

Computer Science Department, Universitat Politècnica de València, Camino de Vera s/n, 46022. Valencia, Spain

agiret@dsic.upv.es

* Corresponding author

ABSTRACT: Despite their potential benefits in the context of sustainable manufacturing operations, holonic and multi-agent architectures are still not designed methodologically to support this major societal and environmental stake. To fill the gap, the generic concept of go-green manufacturing holon is proposed. The idea is to incite researchers to develop sustainability-oriented manufacturing operations control architectures, being holonic or multi-agents, and to provide them with a usable generic concept easy to appropriate, particularize and implement. An illustration of the concept is proposed as well as its widening in the context of circular economy.

\section{Highlights:}

- Current holonic/agent manufacturing control architectures do not handle sustainability.

- The go-green manufacturing holon is proposed to handle sustainability.

- This concept incites researchers to design sustainability-oriented architectures.

- Illustration in opportunistic energy-saving is proposed.

- The work can be extended in the context of circular economy.

Key-words: Sustainable manufacturing, manufacturing operations, holons, agent, effectiveness, efficiency

\section{Introduction}

There exists a huge research activity focusing on industrial sustainability but mainly at strategic (eg., facility layout) and tactical (eg., supply chain) levels [1]. Manufacturing is especially one of the key drivers for industrial sustainability [2], [3]. Here, one of the most recent definitions of sustainable manufacturing has been adopted: "the ability to smartly use natural resources for manufacturing, by creating products and solutions that, thanks to new technology, regulatory measures and coherent social behaviors, are able to satisfy economic, environmental and social objectives, thus preserving the environment, while continuing to improve the quality of human life" [3].

In this letter, the focus is set on manufacturing operations at an operational level. Manufacturing operations deals with activities such as inventory, tooling, production task scheduling, quality control, supervision, maintenance and routing for a given manufacturing system [4].

Designing sustainable manufacturing operation control architectures is now becoming a major issue for researchers but only few activities are led relatively. This letter suggests that, despite the high compatibility of holonic and multi-agent architectures with the need to design sustainable manufacturing operation control systems, most of these architectures have not been designed to support this major societal and environmental need. To fill the gap, the generic concept of go-green manufacturing holon is here proposed to incite to researcher in that field to pay more attention to that crucial need. 


\section{Issues in sustainable manufacturing operations}

Addressing sustainability in manufacturing operations where the complexity of products and processes constantly increases, as well as the competition and the volatility of customers' need, will require to deal with several major issues. First, attention must be paid to the growing unpredictability in the availability of resources such as energy. Second, sustainable manufacturing is a multiple objective problem. It comprises effectiveness-oriented objectives on the one side, which are the classical objectives addressed in the literature and that deal with the evaluation of the results vs. objectives and efficiency-oriented objectives on the other side, less studied, that focus on the evaluation of used and generated means vs. results on the other side [5]. Last, integrating sustainable-oriented mechanisms into manufacturing control decisions requires a fine modeling of manufacturing processes, including multi-physics modeling such as mechanical, energetic and thermic models.

From our point of view, one of the key points in the introduced definition of sustainable manufacturing relies in the word "smartly" and the way researchers implement "smart" or "intelligent" mechanisms to reach sustainable manufacturing [6], [7]. In this letter, the focus is set on holonic (and multi-agent) modelling approaches as a possible way to implement "the smart use" introduced in the definition of [3] to design more sustainable manufacturing operations control systems.

\section{Holonic principles: a suitable approach for sustainable manufacturing operations control}

Holonic principles have been proposed by Koestler [8]. Main principles concern:

- the Janus effect: a holon is a part and a whole at the same time and belongs to a holarchy recursively composed of holons.

- Cooperation/Control: holarchies are by essence cooperation and control-oriented.

- Embedding: each holon is defined by the joining of a physical and an informational part.

Famous architectures like ADACOR [9] and PROSA [10] have been developed according to these principles. Typically, manufacturing operations control holarchies are composed of product holons, resources holons and order holons that interact. These holarchies often integrate in high-level holons (so-called "staff holon" or "supervising holon") some long-term optimization mechanisms (typically, operations research based) and at a lower-level, short-term reactive mechanisms into "local" holons.

As an example, fig. 1 provides a system view of a specific holon, a resource holon, usually met in classical non sustainability-oriented manufacturing control architectures.

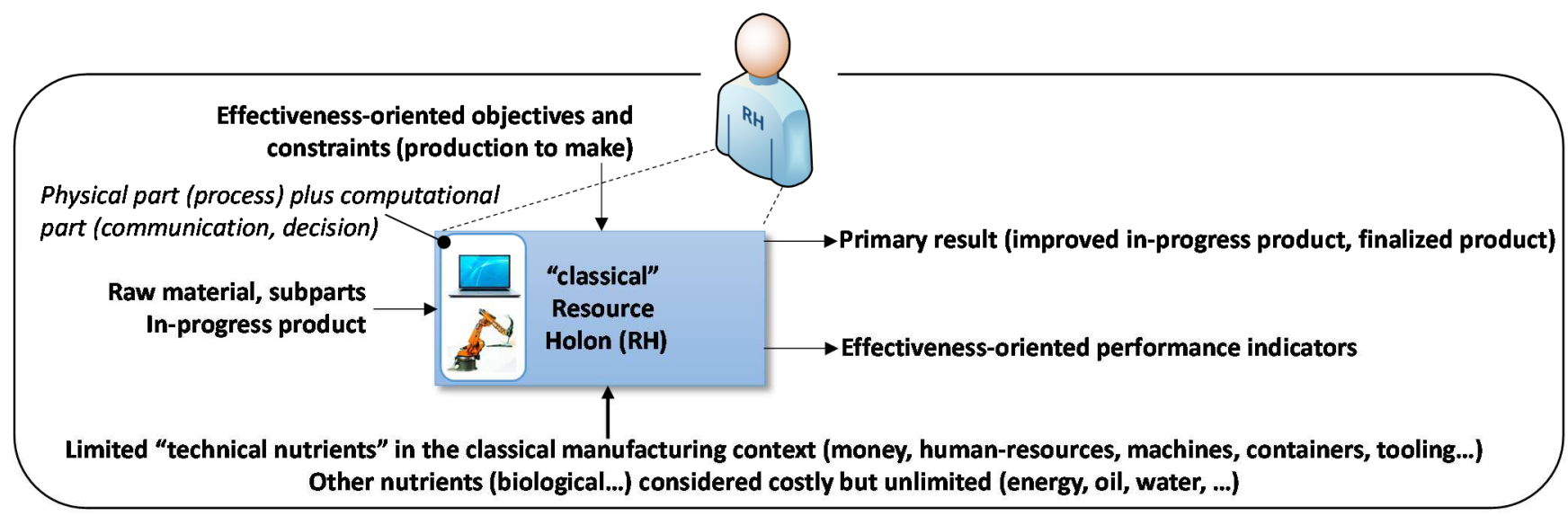

Fig. 1. "Classical" resource holon in manufacturing control. 
Meanwhile, holarchies proposed the literature have never considered sustainability as a key challenge. Despite this lack, the holonic principles are by essence suitable to the context of sustainable manufacturing operations for three main reasons. First of all, with the Janus effect, it may contain recursive mechanisms, enabling the wellknown sustainable principle "think global, act local". Second, holons are reactive and cooperative entities, designed to construct global compromises, which is aligned with the principles of sustainability. Third, holonic principles aim at handling simultaneously the physical and the information parts of a whole holon with a control oriented design approach, which enables easily the integration of sustainable performances criteria related to the use of resources (It is important to note that, from our point of view, if recursivity is not used by designers, holarchies can be modeled as physical multi-agent systems). Last and related to the previous reason, current technology offer enables at a constantly diminishing cost (money, energy, volume) easy implementations of holonic architectures using embedded systems or cyber-physical system approaches [11].

As a consequence, our objective is to encourage researchers working in the field of holonic and multi-agent manufacturing operations control to intentionally design and integrate in their architectures sustainabilityoriented mechanisms. For that purpose, the concept of "go-green manufacturing holons" is proposed.

\section{The go-green manufacturing holon}

The proposed definition is the following: a go green manufacturing holon is a holon that, in the context of sustainable manufacturing, considers when deciding or influencing decisions-by-the-other holons, and regarding manufacturing operations handled by itself or by other holons, complementary efficiency-oriented mechanisms focusing on the means required to realize these operations as well as on the consequence of these operations, aside the production made, in addition to classical effectiveness-oriented mechanisms focusing on this production made.

Beyond effectiveness (typically, time-based and produced quantity-based), efficiency-oriented mechanisms translate the economic, social and environmental dimensions of sustainability. Go-green manufacturing holons may apply different solving approaches: a balanced compromise (between effectiveness and efficiency), a lexicographical-oriented decision making process (eg., optimize first effectiveness, then efficiency in an opportunistic way) or a constrained problem (eg., optimize efficiency under effectiveness constraints). Multicriteria analysis, simulation and operations research approaches can be useful in this context.

In a holarchy, classical and go-green manufacturing holons may coexist. Also, go-green manufacturing holons may address only efficiency issues and could for example, cooperate with classical holons to reach a global consensus. If the recursivity principle is applied [12], a go-green manufacturing holon must be composed at least of a sub gogreen manufacturing holon, dealing with effectiveness-oriented decisions or not.

Fig. 2. provides an example of a go-green (manufacturing) resource holon, to be compared to fig. 1. 


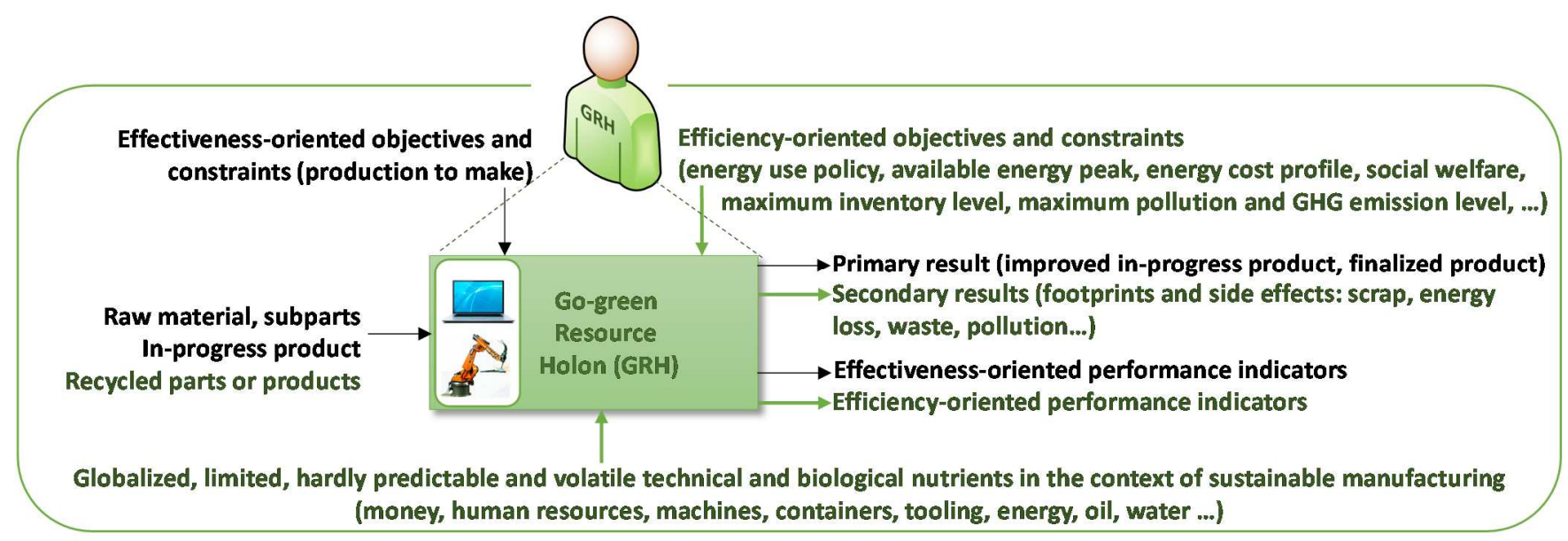

Fig. 2. A go-green resource holon in manufacturing.

\section{Illustration of the proposal in the context of opportunistic energy saving}

The go-green evolution of a previously proposed heterarchical control architecture [13] is proposed as an illustration. The studied flexible manufacturing system (FMS) is described in [14]. Considered manufacturing operations are dynamic production tasks scheduling and products routing. The initial control architecture was composed of products that dynamically sensed potential numerical "attraction fields" emitted by resources. These attractive fields measured the pertinence of a product to route themselves towards a given resource to get a service in due date, depending on the distance and its availability, the higher the attraction, the better the resource (time-based effectiveness: completion time).

The extension towards a go-green manufacturing holarchy is made by defining product holons ( $\mathrm{PH}$ ) and go-green resource holons $(\mathrm{GRH})$ and by introducing a second type of potential fields "intention fields" emitted by $\mathrm{PH}$ towards GRH to diffuse their will to reach their resource, cf. fig. 3. The efficiency-oriented criteria used in GRH is energy waste and GRH integrates now energy consumption models. The novelty is that if not enough intention fields are sensed by GRH, controlled resource go to a sleeping mode, saving energy while not degrading effectiveness-oriented indicators since no PH was to reach them (the chosen solving approach being lexicographical). Saving energy opportunistically is quite hard to realize in a centralized/predictive manner while it is simpler using the proposed approach. The feasibility in a real context has been tested successfully and results are promising since for some experiments led, the reduction of energy consumption for the whole production was about $20 \%$ compared to the initial non-sustainable control system. 


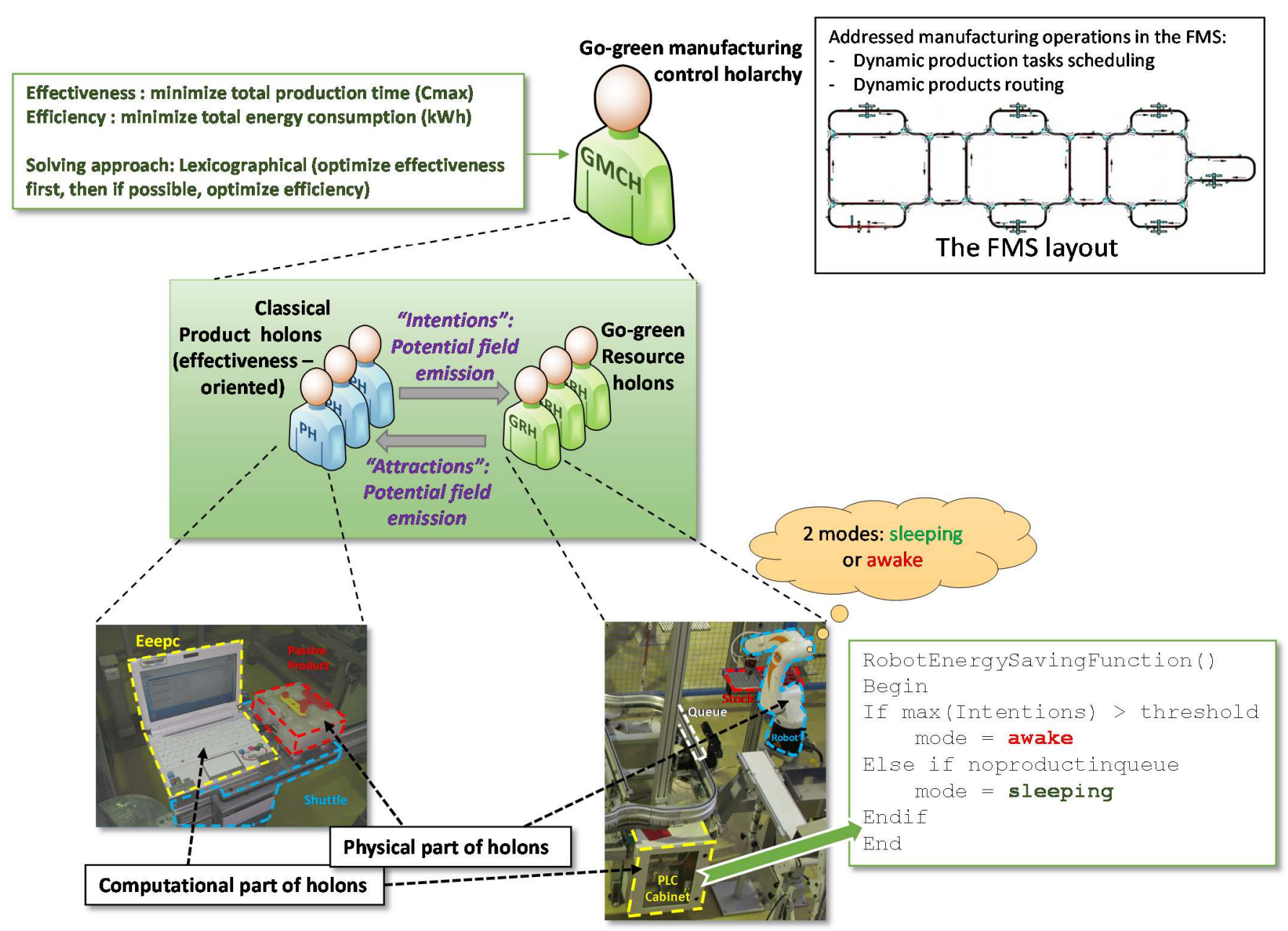

Fig. 3. Proof-of-concept go-green manufacturing operations control holarchy (application on an existing FMS).

\section{Widening to the concept of go-green holon}

The concept of go-green manufacturing holon is proposed here in the context of manufacturing operations. But this concept can be easily extended to encompass other levels of sustainability, beyond manufacturing, for example, in the context of the federative circular economy model [15], cf. fig. 4. Typically, the concept of intelligent product in the use [16] and maintenance [17] phases can be revisited and improved according to the go-green holon concept, as well as the concept of physical internet and intelligent conveyer [18] in transportation/logistics. 


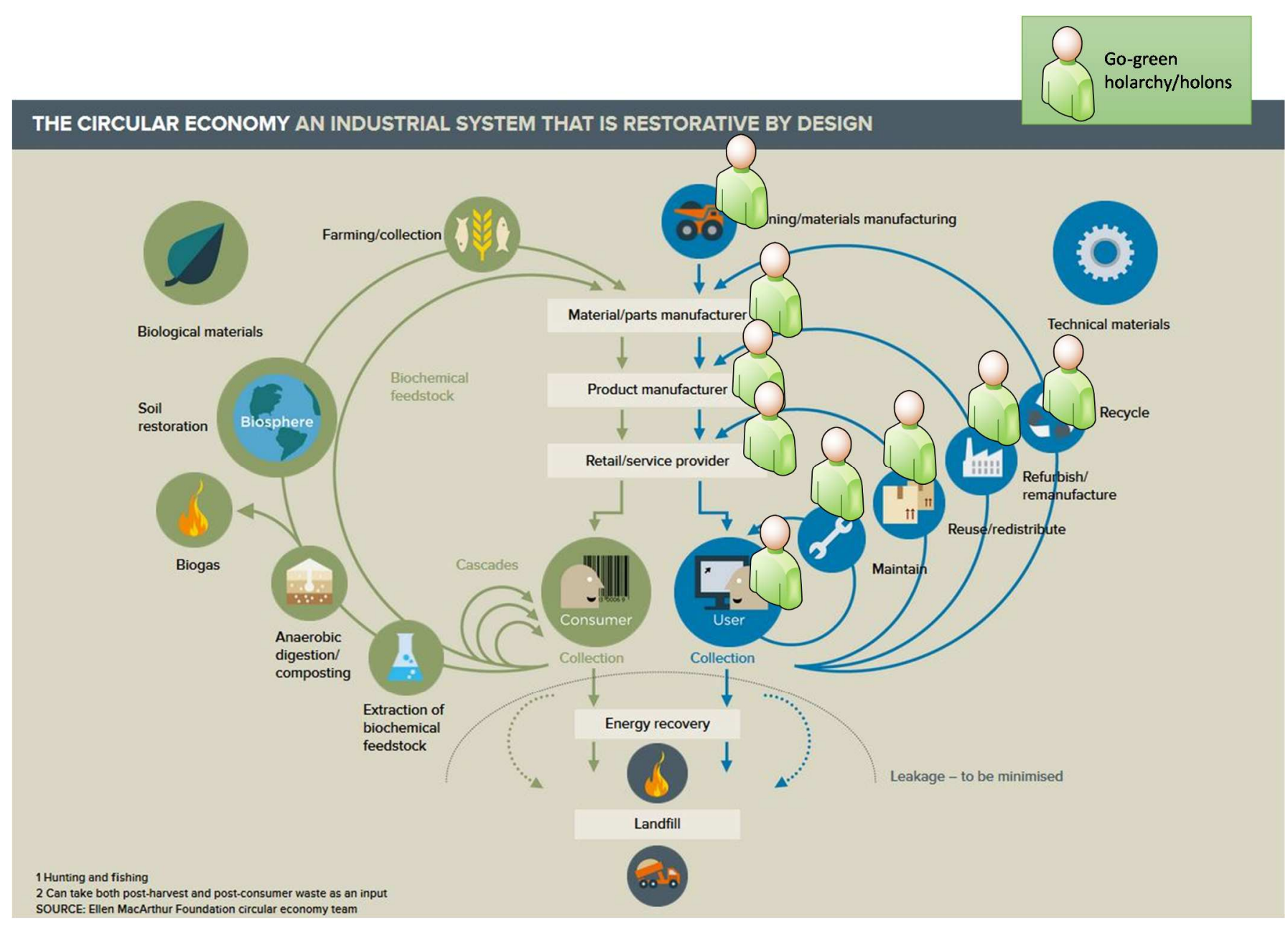

Fig.4. Go-green holon and holarchy: a suitable concept to the circular economy principle.

\section{Conclusion}

In this letter, the concept of go-green manufacturing holon has been proposed and illustrated. Aligned with the ideas presented in [2], the idea is to incite researchers to develop in a methodological way sustainability-oriented manufacturing control architectures, being here holonic or multi-agents and to provide them with a usable generic concept of go-green manufacturing holon easy to appropriate, particularize and implement.

\section{References}

[1] D. Maxwell et R. van der Vorst, " Developing sustainable products and services », Journal of Cleaner Production, vol. 11, n 8, p. 883-895, déc. 2003.

[2] M. Despeisse, F. Mbaye, P. D. Ball, et A. Levers, " The emergence of sustainable manufacturing practices ", Production Planning \& Control, vol. 23, n 5, p. 354-376, 2012.

[3] M. Garetti et M. Taisch, "Sustainable manufacturing: trends and research challenges ", Production Planning \& Control, vol. 23, n 2-3, p. 83-104, 2012.

[4] D. Trentesaux et V. V. Prabhu, "Introduction to shop-floor control », in Wiley Encyclopedia of Operations Research and Management Science, John Wiley \& Sons, Inc., 2013.

[5] D. Trentesaux et V. Prabhu, "Sustainability in Manufacturing Operations Scheduling: Stakes, Approaches and Trends ", in Advances in Production Management Systems. Innovative and Knowledge-Based Production Management in a Global-Local World, B. Grabot, B. Vallespir, S. Gomes, A. Bouras, et D. Kiritsis, Éd. Springer Berlin Heidelberg, 2014, p. 106-113. 
[6] A. Thomas et D. Trentesaux, " Are Intelligent Manufacturing Systems Sustainable? ", in Service Orientation in Holonic and Multi-Agent Manufacturing and Robotics, T. Borangiu, D. Trentesaux, et A. Thomas, Éd. Springer International Publishing, 2014, p. 3-14.

[7] W. F. Gaughran, S. Burke, et P. Phelan, «Intelligent manufacturing and environmental sustainability », Robotics and Computer-Integrated Manufacturing, vol. 23, $n^{\circ}$ 6, p. 704-711, déc. 2007.

[8] A. Koestler, " The ghost in the machine. 1967 », London: Hutchinson, 1967.

[9] P. Leitão et F. Restivo, " ADACOR: A holonic architecture for agile and adaptive manufacturing control », Computers in Industry, vol. 57, $n^{\circ}$ 2, p. 121-130, févr. 2006.

[10] H. Van Brussel, J. Wyns, P. Valckenaers, L. Bongaerts, et P. Peeters, « Reference architecture for holonic manufacturing systems: PROSA », Computers in Industry, vol. 37, n 3, p. 255-274, nov. 1998.

[11] J. Lee, B. Bagheri, et H.-A. Kao, " A Cyber-Physical Systems architecture for Industry 4.0-based manufacturing systems », Manufacturing Letters, vol. 3, p. 18-23, janv. 2015.

[12] S. Suárez, P. Leitao, et E. Adam, " Holonic Recursiveness with Multi-Agent System Technologies ", in Trends in Practical Applications of Agents and Multiagent Systems, J. B. Pérez, J. M. C. Rodríguez, J. Fähndrich, P. Mathieu, A. Campbell, M. C. Suarez-Figueroa, A. Ortega, E. Adam, E. Navarro, R. Hermoso, et M. N. Moreno, Éd. Springer International Publishing, 2013, p. 103-111.

[13] N. Zbib, C. Pach, Y. Sallez, et D. Trentesaux, « Heterarchical production control in manufacturing systems using the potential fields concept ", Journal of Intelligent Manufacturing, vol. 23, n 5, p. 1649-1670, 2012.

[14] D. Trentesaux, C. Pach, A. Bekrar, Y. Sallez, T. Berger, T. Bonte, P. Leitão, et J. Barbosa, « Benchmarking flexible job-shop scheduling and control systems ", Control Engineering Practice, vol. 21, n 9, p. 1204-1225, sept. 2013.

[15] Ellen McArthur Foundation, " Towards the Circular Economy, Economic and Business Rationale for an Accelerated Transition, vol. 1 ». 2013.

[16] M. Kärkkäinen, J. Holmström, K. Främling, et K. Artto, « Intelligent products-a step towards a more effective project delivery chain », Computers in Industry, vol. 50, $n^{\circ}$ 2, p. 141-151, 2003.

[17]A. Le Mortellec, J. Clarhaut, Y. Sallez, T. Berger, et D. Trentesaux, « Embedded holonic fault diagnosis of complex transportation systems ", Engineering Applications of Artificial Intelligence, vol. 26, $n^{\circ}$ 1, p. 227-240, janv. 2013.

[18] E. Ballot, O. Gobet, et B. Montreuil, « Physical Internet Enabled Open Hub Network Design for Distributed Networked Operations ", in Service Orientation in Holonic and Multi-Agent Manufacturing Control, vol. 402, T. Borangiu, A. Thomas, et D. Trentesaux, Éd. Berlin: Springer-Verlag Berlin, 2012, p. 279-292. 